\title{
Heat transfer intensity of pulsating gas flows in the exhaust system elements of a piston engine
}

\author{
L. V. Plotnikov ${ }^{1, *}, Y . M$. Brodov $^{1}$, and $M . O$. Misnik $^{1}$ \\ ${ }^{1}$ Ural Federal University named after the first President of Russia B.N. Yeltsin, Ekaterinburg, Russia
}

\begin{abstract}
Internal combustion engines are the most common sources of energy among heat engines. Therefore, the improvement of their design and workflow is an urgent task in the development of world energy. Thermal-mechanical perfection of the exhaust system has a significant impact on the technical and economic performance of piston engines. The article presents the results of experimental studies of gasdynamics and heat exchange of pulsating gas flows in the exhaust system of a piston engine. Studies were carried out on a full-scale model of a single-cylinder engine. The article describes the instrument-measuring base and methods of experiments. The heat transfer intensity was estimated in different elements of the exhaust system: the exhaust pipe, the channel in the cylinder head, the valve assembly. Heat transfer studies were carried out taking into account the gas-dynamic nonstationarity characteristic of gas exchange processes in engines. The article presents data on the influence of gas-dynamic and regime factors on the heat transfer intensity. It is shown that the restructuring of the gas flow structure in the exhaust system occurs depending on the engine crankshaft speed, this has a significant impact on the local heat transfer coefficient. It has been established that the heat transfer intensity in the valve assembly is 2-3 times lower than in other elements of the exhaust system.
\end{abstract}

\section{Introduction}

One of the ways to improve the performance of piston internal combustion engines (ICE) is to improve its workflow [1-3]. The heat transfer intensity in the exhaust system significantly affects several technical and economic indicators of the engine, such as external heat balance, average cycle temperature, temperature stresses of the exhaust system components (exhaust valve, cylinder head, exhaust manifold, etc.). A large number of multidirectional works devoted to the study of processes in the exhaust system of the ICE. There are studies of physical processes in the exhaust system based on mathematical modelling in order to improve the technical and environmental parameters of piston engines. For example, in the articles [4-6] the adjustment of the geometric dimensions of the parts of the exhaust system of gasoline engines is made, and in the articles [7-9] similar studies are performed with respect to diesel engines. Kumar K.M. and Munjal M.L. [10] investigated the acoustic characteristics of exhaust systems of different configurations. Sahoo D.K. and Thiya R. [11] studied the effect of heat transfer intensity on thermal stresses in the details of the exhaust system. It should be noted that in most cases mathematical modelling of gas dynamics and heat exchange of gas flows is performed in stationary conditions. There are also works based on experimental studies that are devoted to this subject [12, 13]. At the same time, it is possible to distinguish works in which the simulation results are verified by experimental studies $[14,15]$.

Data on instantaneous local heat transfer are needed to calculate heat flow and to determine the temperature stresses in the cylinder head and exhaust pipe. Since it is known that the heat transfer coefficient in non-stationary conditions may differ from the stationary case by $2-4$ times $[16,17]$. Thus, the purpose of this study was to obtain data on the heat transfer intensity in different elements of the exhaust system under the conditions of gas-dynamic non-stationarity (pulsating gas flows).

\section{Experimental base}

The studies were conducted on a full-scale model of a piston engine (cylinder diameter $82 \mathrm{~mm}$, piston stroke 71 $\mathrm{mm}$ ) in order to establish the influence of gas-dynamic non-stationarity on the heat transfer intensity in different elements of the exhaust system of the ICE. The gas distribution mechanism of the experimental setup was borrowed from the VAZ-OKA automobile engine. The timing and lift valves of the installation corresponded to those for this engine. The camshaft was driven by an asynchronous electric motor, whose rotational speed was regulated by a frequency converter in the range of 300$1500 \mathrm{rpm}$. This range corresponds to the crankshaft rotation speed $\mathrm{n}$ from 600 to $3000 \mathrm{rpm}$. The experimental setup is described in more detail in [17].

The configuration of the investigated area of the exhaust system of the experimental setup and the

\footnotetext{
* Corresponding author: plotnikovlv@ mail.ru
} 
installation location of the sensors for measuring the instantaneous values of the air flow rate and local heat transfer are shown in Figure 1. Thus, three control sections were investigated in this work: near the valve, in the channel in the cylinder head and in the exhaust pipe.

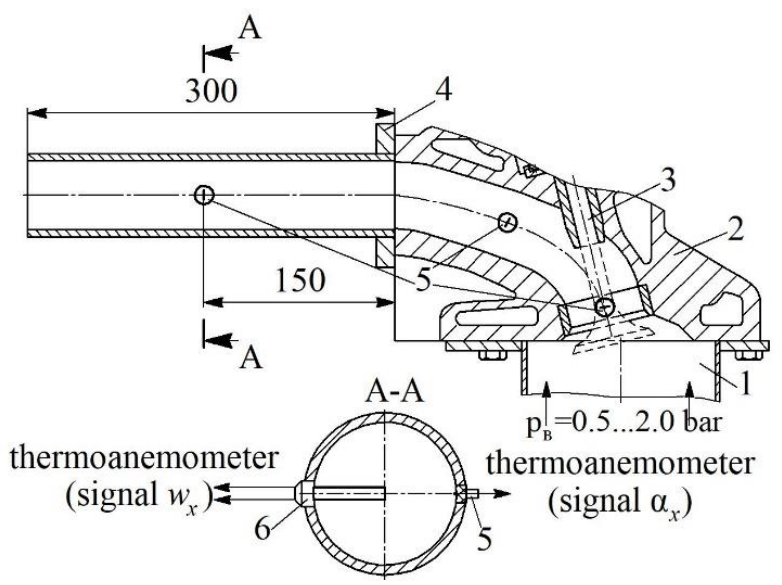

Fig. 1. Configuration of the exhaust system of the experimental setup and location of sensors: 1 - cylinder; 2 - block head; 3 exhaust valve; 4 - exhaust pipe; 5 - thermo-anemometer sensors for determining the local heat transfer coefficient; 6 thermo-anemometer sensors for determining the flow velocity.

Investigations were carried out for different crankshaft rotational speeds (from 600 to $3000 \mathrm{rpm}$ ) at various constant overpressure at the output of $p_{b}$ (from 0.5 to 2.0 bar) without using a noise silencer. The air temperature in the channel was $22-24^{\circ} \mathrm{C}$.

An automated system based on an analog-to-digital converter was created to make the necessary measurements. The system converted analog signals to digital form and transferred the data to a personal computer for processing. A constant-temperature thermo-anemometer was used to determine the instantaneous values of both the air flow rate $w_{x}$ and the local heat transfer coefficient $\alpha_{x}$. In both cases, a nichrome thread with a diameter of $5 \mu \mathrm{m}$ and a length of $5 \mathrm{~mm}$ was a sensitive element of the thermo-anemometer sensors. A sensor with a free thread placed perpendicular to the axis of the outlet channel was used to measure the air flow rate. A sensor with a thread lying on a fluoroplastic substrate was used to determine the coefficient $\alpha_{x}$. The substrate with the sensing element was installed flush with the wall of the channel under study. Measurement of the rotational speed and indication of the camshaft position were made with a tachometer. The tachometer consisted of a gear disk mounted on the shaft, and an inductive sensor. The position of the crankshaft (the piston passage of the top and bottom dead points) was determined from these data. The methodology for conducting experiments is also described in more detail in [17].

\section{The results of experimental studies}

Analysis of the heat exchange characteristics of the exhaust process will begin with a control section located in the exhaust pipe. The dependences $w_{x}=f(\tau)$ and $\alpha_{x}=$ $f(\tau)$ for overpressure $p_{b}=2.0$ bar and at different $n$ are presented in Figure 2.
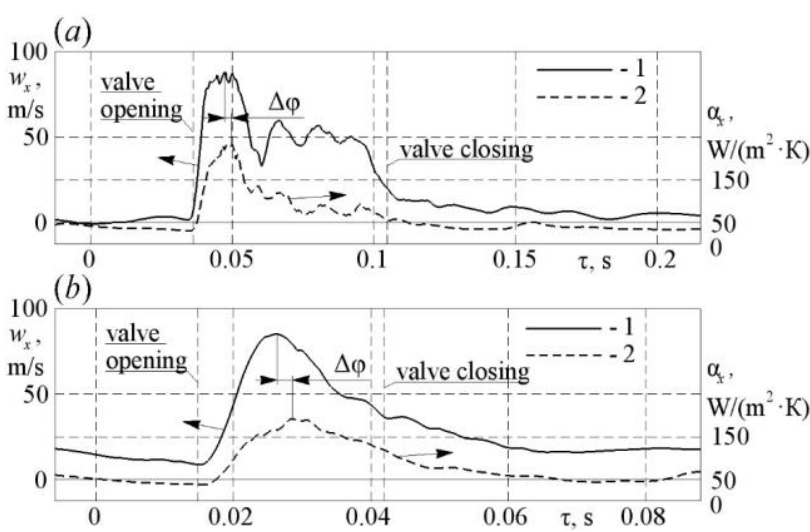

Fig. 2. Dependencies of air flow rate $w_{x}(1)$ and local heat transfer coefficient $\alpha_{x}(2)$ on time $\tau$ in the exhaust pipe with an overpressure of $p_{b}=2.0$ bar for different rotational frequencies of the crankshaft: $\mathrm{a}-n=600 \mathrm{rpm} ; \mathrm{b}-n=3000 \mathrm{rpm}$.

When determining the gas-dynamic conditions of heat transfer in the exhaust pipe, it was found that pulsations of the air flow rate are most pronounced at low crankshaft rotational frequencies for all values of overpressure (Figure 2,a). It should be noted that the opposite effect was observed in the intake system of a piston ICE [18]: the dynamics of gas-dynamic processes became more complex with an increase in the rotational speed of the crankshaft (more pronounced pulsations of velocity and pressure of air flow were recorded).

It is noteworthy that the air flow rate does not become zero after closing the exhaust valve and some velocity fluctuations are observed. There is a similar effect for the flows in the intake system, where the air flow rate also does not vanish after the intake valve is closed [18].

The influence of gas-dynamic factors is manifested in the dynamics of the heat transfer process. The lag in the change in the heat transfer intensity from the change in the air flow rate by the value $\Delta \varphi$ is observed (Figure 2). The value $\Delta \varphi$ increases with increasing crankshaft rotation frequency for all values of overpressure $p_{b}$ and in all studied sections. It can also be noted that the form of the local heat transfer coefficient curve becomes smoother at high crankshaft speeds.

On this basis, it can be assumed that several modes of gas flow in the exhaust system arise, which are determined by the crankshaft rotation frequency. The physical features of these modes affect the flow structure, which determines the intensity of the local heat transfer coefficient. Therefore, it is necessary to consider the gas-dynamic features of the flows in the exhaust system in more detail in order to present the physical mechanism for changing the local heat transfer coefficient at different engine speeds. The normalized amplitude-frequency spectra of pulsations of the air flow rate in the exhaust pipe of the piston ICE with an overpressure of 2.0 bar and for different frequencies of rotation of the crankshaft are presented in Figure 3. 

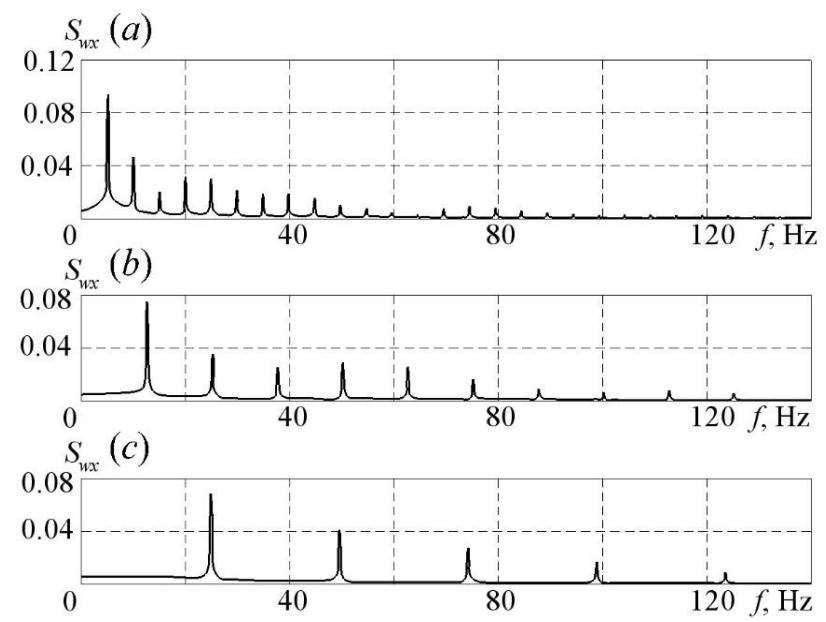

Fig. 3. Amplitude-frequency spectra of air flow velocity pulsations $w$ in the exhaust pipeline at $p_{b}=2.0$ bar for different crankshaft speeds: $\mathrm{a}-n=600 \mathrm{rpm} ; \mathrm{b}-n=1500 \mathrm{rpm}$;

$\mathrm{c}-n=3000 \mathrm{rpm}$.

It has been established that significant frequencies of the spectrum are multiple for all values of the crankshaft rotation frequency. For example, these frequencies are equal to $5,10,15,20 \mathrm{~Hz}$, and so on for $n=600 \mathrm{rpm}$. The multiplicity increases with increasing crankshaft rotation frequency. Significant frequencies extend to $50 \mathrm{~Hz}$ and their multiplicity is 5 at $n=600 \mathrm{rpm}$. Significant frequencies are shifted to higher values (up to 80 and $120 \mathrm{~Hz}$ ) and their multiplicity also increases (12.5 and 25) for higher values of $n$.

Thus, the analysis of the amplitude-frequency spectra and gas-dynamic characteristics of pulsating flows in the exhaust pipe of a piston ICE indicates that the change in the flow regime occurs and the air flow structure changes with the growth of the crankshaft rotation frequency. This leads to the transformation of the dependence of the local heat transfer coefficient over time. With an increase in the crankshaft rotation frequency $n$, a decrease in the maximum values of the local heat transfer coefficient $\alpha_{x}$ is observed, as well as an expected shift of the peaks of speed and heat transfer over time occurs (see Figure 2). The most significant displacements are observed at $\mathrm{n}=3000 \mathrm{rpm}$.

Further, the heat exchange characteristics of the flow in different parts of the exhaust system will be considered. The dependences of the local heat transfer coefficient $\alpha_{x}$ over time $\tau$ for all three studied control sections at the different crankshaft rotation frequencies $n$ are shown in Figure 4. These data are important in terms of estimating thermal stresses in the parts and nodes of the exhaust system [19].

The figure shows that the maximum values of the local heat transfer coefficient are virtually the same for the channel in the cylinder head and for the exhaust pipe, which is typical for all crankshaft rotational speeds. It should also be noted that the function of changing heat transfer over time is practically identical for the cases under consideration (control sections and rotational frequencies). (a)

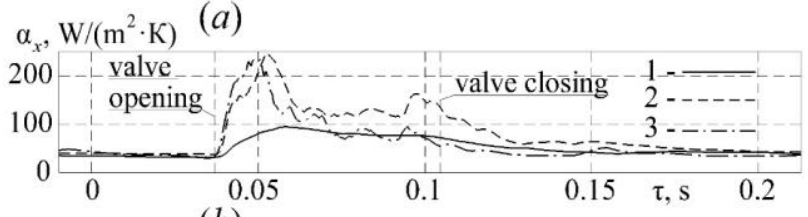

$\alpha_{x}, \mathrm{~W} /\left(\mathrm{m}^{2} \cdot \mathrm{K}\right)(b)$

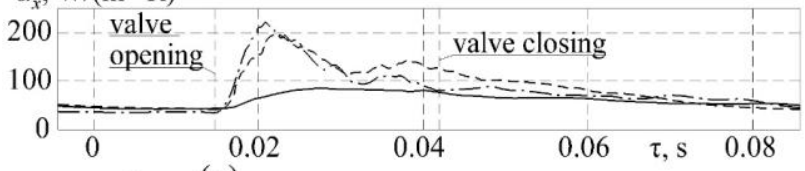

$\alpha_{x}, \mathrm{~W} /\left(\mathrm{m}^{2} \cdot \mathrm{K}\right)(c)$

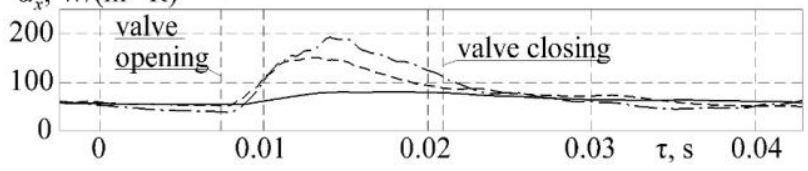

Fig. 4. Dependencies of the local heat transfer coefficient $\alpha_{x}$ in the exhaust system on time $\tau$ at an overpressure of $p_{b}=2.0 \mathrm{bar}$ for different crankshaft rotational speeds: $\mathrm{a}-n=600 \mathrm{rpm} ; \mathrm{b}-$ $n=1500 \mathrm{rpm}$; c $-n=3000 \mathrm{rpm}$; Control section: $1-$ near the valve; 2 - channel in the cylinder head; 3 - exhaust pipe.

However, the change in the local heat transfer coefficient in the control section near the exhaust valve is noteworthy. The curve shape $\alpha_{x}=f(\tau)$ is much smoother than in other sections. At the same time, the maximum values of $\alpha_{x}$ in this section are 2-3 times less than in other cases, which is also characteristic of all crankshaft rotational speeds. These dependences look rather strange, since the gas flow rate near the exhaust valve is noticeably higher than in other control sections of the exhaust system. However, this phenomenon can be explained by the fact that stagnant zones are formed near the exhaust valve, which can prevent heat exchange and, accordingly, reduce the heat transfer intensity [2]. According to the authors, in our case there is a similar phenomenon.

\section{Conclusions}

According to the results of the conducted research, it can be concluded that the instantaneous local heat transfer coefficient is most significantly dependent on the engine crankshaft rotational speed and the configuration of the exhaust system element under study. In this case, the restructuring of the flow structure in the exhaust system occurs with an increase in the rotation frequency $n$; this affects the gas-dynamic, consumable and heat exchange characteristics of the pulsating flow in the exhaust system of a piston ICE. The observed patterns complicate the task of calculating temperature stresses in the cylinder head and exhaust pipe, since there is a need to take into account the gas-dynamic non-stationarity of processes in the exhaust system. Thus, to calculate the intensity of heat transfer in the elements of the exhaust system, it is necessary to apply only empirical expressions of heat transfer, which take into account the dynamics of this process for a specific engine size.

The work has been supported by the Russian Science Foundation (grant No. 18-79-10003). 


\section{References}

[1] J.B. Heywood Internal combustion engine fundamentals (New York: McGraw-Hill) 458 (1988)

[2] B.H. Draganov, M.G. Kruglov, V.S. Obuhova Construction of intake and exhaust channels of internal combustion engines (Kiev: Vishcha shkola) 175 (1987)

[3] M.M. Vihert, Yu.G. Grudskij, Construction of the intake systems of high-speed diesel engines (Moscow: Mashinostroenie) 151 (1982)

[4] S. Bari, SAE Technical Papers 2019 April (2019)

[5] B. Worsztynowicz, M. Perek, IOP Conf. Series: Materials Science and Engineering 421(4), 042083 (2018)

[6] A.B. Shahriman, A.K. Mohamad Syafiq, M.S.M. Hashim, Z.M. Razlan, W.A.N. Khairunizam, D. Hazry, M. Afendi, R. Daud, M.D.T.A. Rahman, E.M. Cheng, S.K. Zaaba, AIP Conf. Proceedings 1885020120 (2017)

[7] J.M. Luján, J.R. Serrano, P. Piqueras, Diesel B Applied Energy 409-423 (2019)

[8] T.J.J. Wang Mechanical Science and Technology 32(7), 3465-3472 (2018)

[9] A.J. Torregrosa, A. Broatch, F.J. Arnau, M. Hernández, Int. J. Mechanical Sciences 133, 740-751 (2017)

[10] K.M. Kumar, M.L. Munjal, Applied Acoustics 149, 171-180 (2019)

[11] D.K. Sahoo, R. Thiya Int. J. Ambient Energy 40(4), 361-366 (2019)

[12] J. Jang, Y. Woo, Y. Jung, C. Cho, G. Kim, Y. Pyo, M. Han, S. Lee, Int. J. Energy Research 42(9), 3007-3016 (2018)

[13] M.W. Bae, Y.J. Ku, H.S. Park Trans. Korean Soc. Mechanical Engineers, B 41(11), 775-784

[14] Y.A. Grishin, V.A. Zenkin, R.N. Khmelev, 2017 J. Engineering Physics and Thermophysics 90(4), 965-970 (2017)

[15] C.C. Ma, L.W. Sun, N. Fang, H. Zhang, Trans. Beijing Inst. Technology 37(9), 919-925 (2017)

[16] I.A. Davletshin, N.I. Mikheev, A.A. Paereliy, I.M. Gazizov, 2019 Int. J. Heat Mass Transfer 129, 7485

[17] L.V. Plotnikov, B.P. Zhilkin, Int. J. Heat Mass Transfer 115, 1182-1191 (2017)

[18] L.V. Plotnikov, B.P. Zhilkin, Y.M. Brodov, Procedia Engineering 206, 80-85 (2017)

[19] Y.M. Brodov, N.I. Grigoryev, B.P. Zhilkin, L.V. Plotnikov, D.S. Shestakov, Thermal Engineering 62(14), 1038-1042 (2015) 